\title{
Determinação de plantas indicadoras de resíduos de bentazona, atrazina e clomazona no solo
}

\section{Determination of indicator plants for residues of bentazone, atrazine, and clomazone in the soil}

\author{
Jaqueline Franciosi Della Vechia'*, Lorena Regina da Silva Peres², Pâmela Pereira Castro, \\ Claudinei da $\mathrm{Cruz}^{2}$ \\ ${ }^{1}$ Universidade Estadual Paulista "Júlio de Mesquita Filho", Jaboticabal-SP, Brasil. \\ ${ }^{2}$ Centro Universitário da Fundação Educacional de Barretos, Barretos-SP, Brasil.
}

\begin{abstract}
Resumo
O monitoramento ambiental de resíduos de herbicidas em solos, durante e após os ciclos culturais, auxilia na tomada de decisão sobre os procedimentos do manejo a ser adotado. O estudo da dinâmica ambiental de herbicidas pode ser realizado com o auxílio de plantas que indicam a qualidade do solo. Diante disso, o objetivo deste estudo foi avaliar o efeito sobre a intoxicação e crescimento das plantas indicadoras de milho (Zea mays), rabanete (Raphanus sativus) e abóbora (Cucurbita moschata) expostas aos herbicidas atrazina, bentazona e clomazona. Os ensaios foram realizados em sala com condições controladas de temperatura, umidade e intensidade de luz. As plantas foram mantidas em recipientes contendo areia lavada (substrato inerte). Foram testadas sete concentrações de cada herbicida $(0,0 ; 1,0 ; 5,0 ; 10,0 ; 25,0$; 50,$0 ; 75,0$; e 100,0 mg kg-1). Avaliações de intoxicação e comprimento das plantas de milho, rabanete e abóbora foram realizadas aos 14 dias após a aplicação dos herbicidas. Todas as espécies testadas foram sensíveis à bentazona, atrazina e clomazona, no entanto, o nível de sensibilidade na resposta aos herbicidas foi dependente da espécie e concentração. A planta de milho é um potencial indicador do clomazona, enquanto rabanete e abóbora são potenciais indicadoras dos três herbicidas avaliados.
\end{abstract}

Palavras-chave: Cucurbita moschata, efeito residual, Raphanus sativus, sucessão de culturas, Zea mays.

\begin{abstract}
Environmental monitoring of herbicide residues in soils during and after cultural cycles is important to assist in decision-making on the management procedures to be adopted. Studies with plants that indicate soil quality are essential for understanding the environmental dynamics of herbicides. Therefore, the objective of this study was to evaluate the effect on the intoxication and growth of the indicator plants of corn (Zea mays), radish (Raphanus sativus), and pumpkin (Cucurbita moschata) exposed to the atrazine, bentazone and, clomazone herbicides. Tests were carried out in a room with controlled conditions of temperature, humidity, and light intensity. Plants were kept in containers containing washed sand (inert substrate). Seven concentrations of each herbicide $\left(0.0 ; 1.0 ; 5.0 ; 10.0 ; 25.0 ; 50.0 ; 75.0\right.$ and $\left.100.0 \mathrm{mg} \mathrm{kg}^{-1}\right)$ were tested. Intoxication and length evaluations of corn, radish, and pumpkin plants were carried out 14 days after herbicide application. All species tested were sensitive to bentazone, atrazine, and clomazone, however, the level of sensitivity in response to herbicides depended on the species and concentration. The corn plant is a potential indicator of clomazone, whereas radish and pumpkin are potential indicators of all three herbicides evaluated.
\end{abstract}

Keywords: Cucurbita moschata, residual effect, persistence, Raphanus sativus, succession cultures, Zea mays

\footnotetext{
*Autor para correspondência: Jaqueline Franciosi Della Vechia, e-mail: jaquelinefdv@gmail.com Recebido para publicação: 06/jul/2020.

Aceito para publicação: 13/maio/2021
}

https://doi.org/10.4322/1980-0029.132020 


\section{Introdução}

O controle químico de plantas daninhas destaca-se por ser um método eficiente, rápido e econômico (Silva et al., 2007), sendo a interferência de biomassa destas plantas o principal fator de perdas de produção (Colbach \& Stéphane Cordeau, 2018). Os herbicidas que permanecem no solo por longos períodos são importantes para a garantia da produtividade das culturas comerciais, entretanto, a sua presença pode se tornar indesejável e gerar efeitos de intoxicação de culturas em sequência (Dan et al., 2011). A presença desses resíduos por tempo excedente ao período útil, ou seja, o período de competição das plantas daninhas, é indesejável, porque pode provocar injúrias às culturas em rotação/sucessão, pode atingir níveis que afetariam o desenvolvimento de microrganismos do solo e potencial na contaminação do lençol freático (Reis et al., 2008, Scheil et al., 2009).

Alguns herbicidas como a atrazina (2-cloro4-etilamino-6-isopropilamino-s-triazina) são considerados poluentes ambientais de solo e água com significativa toxicidade para os seres humanos e ecossistemas (Douglass et al., 2017, Sanchez et al., 2017). O herbicida bentazona (2,2-dióxido de 3-isopropil $(1 \mathrm{H})$-benzo-2,1,3-triadizin-4-ona) impede a fotossíntese mediante inibição da reação de Hill, provocando clorose e necrose foliar. Um efeito secundário causado pela ação fotossintética é a inibição do crescimento (Ferhatoglu \& Barret, 2006). Clomazona $\{2-[(2-$ clorofenil $)$ metil]-4,4dimetil-3-isoxazolidinona) $\}$, pertencente ao grupo químico das isoxazolinonas, causa danos no cloroplasto, que resulta na inibição da formação de pigmentos fotossintéticos, reduzindo a síntese de caroteno (Rodrigues \& Almeida, 2018). Esses três herbicidas possuem amplo espectro de ação e são utilizados em diversas culturas. Relatos de toxicidade em cultivos de sucessão/rotação já foram registrados para estes herbicidas (Brighenti et al., 2002, Dayan et al., 2009, Nogueira \& Correia, 2016).

O monitoramento ambiental de resíduos, a inibição de crescimento vegetal ou efeitos de toxicidade residual de herbicidas em solos durante e após os ciclos culturais têm alcançado destaque, visto que estes estudos auxiliam na tomada de decisão sobre os procedimentos de manejo a ser adotado em função dos efeitos acima descritos. Uma técnica comum para identificar um herbicida no solo é por meio de bioensaios, utilizando-se plantas indicadoras que apresentam fácil cultivo, rápido desenvolvimento e alta sensibilidade aos herbicidas avaliados (Nyffeler et al., 1982; Souza et al., 1999). Exemplos de bioensaios para essa finalidade são avaliação de toxicidade em plantas indicadoras e o comprimento delas.

As plantas indicadoras respondem aos herbicidas por meio de reações comportamentais ou metabólicas mensuráveis, por exemplo: razão de crescimento, germinação ou desenvolvimento de caules e raízes (Organization for Economic Co-operation, Development, 1984), que indicam e refletem alguma mudança no ambiente onde vivem e são utilizadas para caracterizar a saúde do ambiente, indicar o grau de perigo e dar suporte às determinações dos possíveis riscos ecológicos (United State of America Agency Environmental Protection, 2002). Estes fatores salientam a importância dos estudos com plantas que indicam a qualidade ambiental do solo para o conhecimento da dinâmica ambiental de herbicidas. Perante o exposto, o objetivo deste estudo foi avaliar o efeito sobre a intoxicação e crescimento das plantas indicadoras de milho (Zea mays), rabanete (Raphanus sativus) e abóbora (Cucurbita moschata) expostas aos herbicidas atrazina, bentazona e clomazona.

\section{Material e Métodos}

Os herbicidas selecionados para os ensaios foram: atrazina $\left(500,0 \mathrm{~g} \mathrm{~L}^{-1}\right.$ - Atrazina Nortox $500 \mathrm{SC})$, clomazona $\left(360,0 \mathrm{~g} \mathrm{~L}^{-1}-\mathrm{Gamit}^{\circledR} 360\right.$ CS) e bentazona $\left(600,0 \mathrm{~g} \mathrm{~L}^{-1}-\mathrm{Amplo}^{\circledR}\right)$.

Os ensaios de toxicidade aguda (teste de vigor) para as plantas indicadoras foram conduzidos conforme recomendação da ABNT (Associação Brasileira de Normas Técnicas, 2009). Para tanto, a areia (substrato inerte) foi previamente lavada e seca à temperatura ambiente e, em seguida, peneirada em peneiras de malha de 2 a $4 \mathrm{~mm}$.

Para obtenção das plantas utilizadas nos ensaios, sementes de milho (Z. mays) e rabanete (R. sativus) foram semeadas em bandejas de germinação contendo substrato orgânico e, quando as plantas apresentaram duas folhas verdadeiras, três plantas foram transplantadas para recipientes plásticos contendo $300 \mathrm{~g}$ de areia lavada. Para obtenção das plantas de abóbora (C. moschata), foram selecionadas três sementes e semeadas em recipientes plásticos contendo $300 \mathrm{~g}$ de areia.

Em sala com condições controladas, temperatura de $27,0 \pm 2,0^{\circ} \mathrm{C}$ e fotoperíodo de 12 horas de luz, 
com iluminação de 1000 lux (Associação Brasileira de Normas Técnicas, 2009), foram conduzidos simultaneamente ensaios para as plantas de milho, rabanete e abóbora. $\mathrm{O}$ delineamento experimental utilizado nos três ensaios foi inteiramente casualizado com cinco repetições e o período de avaliação foi de 14 dias. Para a análise dos dados de comprimento das plantas, os tratamentos foram dispostos em esquema fatorial $3 \times 7$, sendo os fatores representados pelos herbicidas (atrazina, clomazona e bentazona) e sete concentrações testadas 0,$0 ; 1,0 ; 10,0 ; 25,0 ; 50,0 ; 75,0 ;$ e 100,0 $\mathrm{mg} \mathrm{kg}^{-1}$ de ingrediente ativo.

Para a diluição de cada concentração a ser testada, foram utilizados como solução de diluição $70,0 \mathrm{~mL}$ de água destilada, equivalente à máxima umidade da areia, previamente aferida. A cada 48 horas, foram repostos $50,0 \mathrm{~mL}$ de água em cada unidade experimental para manter a umidade da areia e não ocorrer limitação para o desenvolvimento das plantas indicadoras. Após 14 dias da aplicação dos herbicidas (DAA), avaliou-se a porcentagem de intoxicação das plantas atribuindo notas de 0 (ausência de sintoma) a 100 (morte da planta) (Asociación Latinoamericana de Malezas, 1974) e comprimento $(\mathrm{cm})$ das plantas (Organization for Economic Co-operation, Development, 1984).
Os dados de comprimento das plantas foram submetidos à análise de variância e as médias foram comparadas entre si utilizando o teste de Tukey a $5 \%$ de probabilidade $(P<0,05)$, com o programa estatístico AgroEstat (Barbosa \& Maldonado Júnior, 2013).

\section{Resultados e Discussão}

Todas as espécies testadas foram sensíveis à bentazona, atrazina e clomazona. As plantas de milho apresentaram sinais caracterizados por limitação no porte, branqueamento no limbo foliar e necrose nos bordos foliares quando expostas à clomazona, principalmente a partir da dose de $10 \mathrm{mg}$ i.a. $\mathrm{kg}^{-1}$. O maior nível de intoxicação observado para plantas de milho foi de $80 \%$ na maior concentração de clomazona (Figura 1). As plantas de rabanete apresentaram sinais caracterizados por clorose e necrose no limbo foliar quando expostas à concentração de $1,0 \mathrm{mg}$ i.a. $\mathrm{kg}^{-1} \mathrm{de}$ clomazona. Nas demais concentrações, os sinais de intoxicação foram mais acentuados, atingindo $100 \%$ de intoxicação na maior concentração (Figura 1). Em consequência da alta intoxicação, as plantas de rabanete apresentaram redução no porte de $28 \%$ e $32 \%$ nas duas maiores concentrações testadas (Tabela 1).
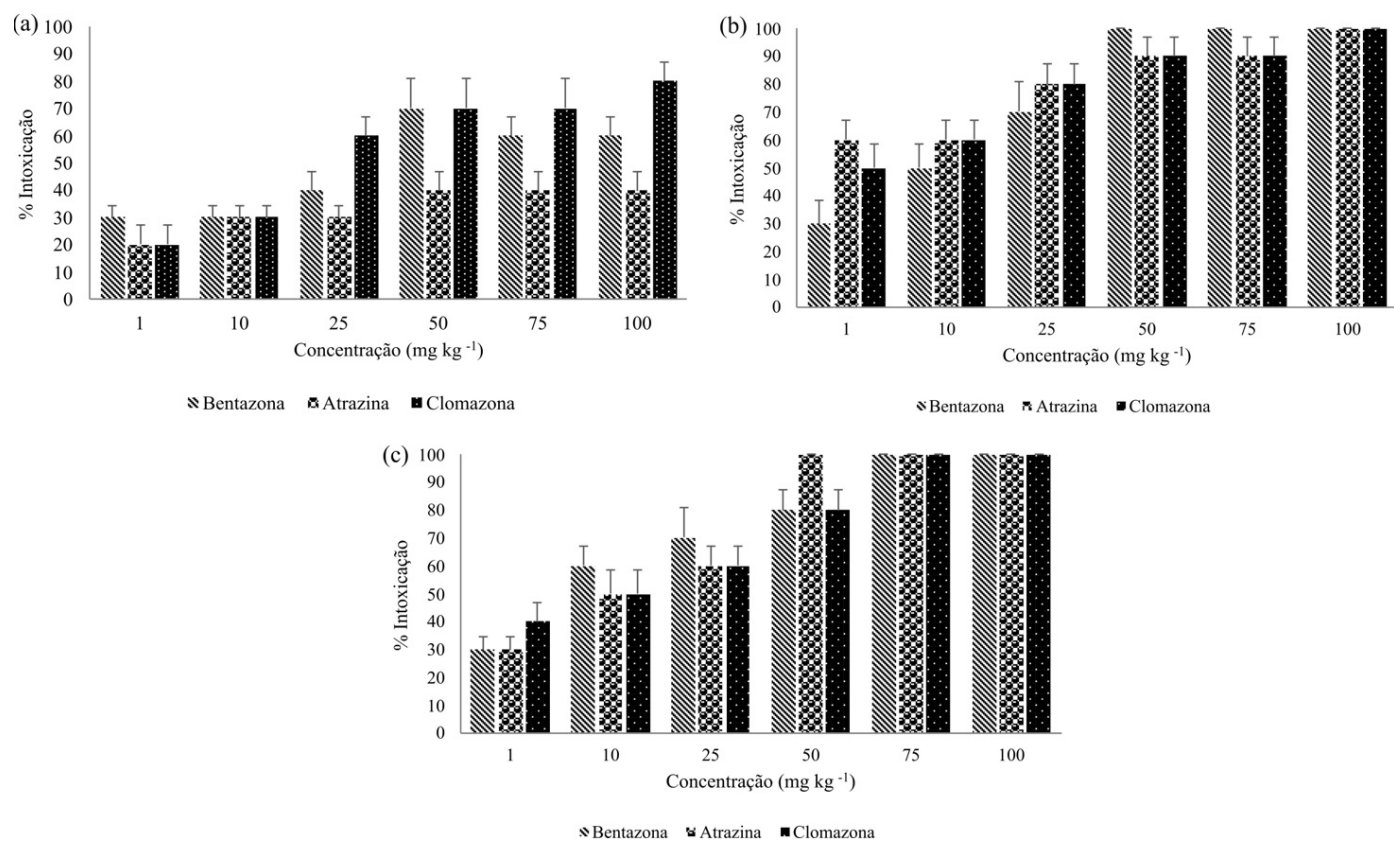

Figura 1. Efeito de concentrações de bentazona, atrazina e clomazona na porcentagem de intoxicação de plantas de milho (a), rabanete (b) e abóbora (c), aos 14 DAA. 
O principal sinal de intoxicação das plantas de abóbora foi clorose dos limbos foliares a partir da concentração de $1 \mathrm{mg} \mathrm{kg}^{-1}$ dos três herbicidas. Clomazona proporcionou necrose das plantas a partir da concentração $75 \mathrm{mg} \mathrm{kg}^{-1}$, o que causou níveis de $100 \%$ de intoxicação (Figura 1). Embora a máxima intoxicação das plantas de abóbora tenha sido nas duas maiores concentrações, a limitação do porte das plantas ocorreu a partir da menor dose testada (Tabela 1).

O efeito de clorose no limbo foliar das plantas testadas, quando expostas à clomazona, se deve ao mecanismo de ação deste produto que consiste em inibir a síntese de carotenoides (Ferhatoglu \& Barret, 2006). O sinal evidenciado pelas plantas tratadas é a produção de tecidos totalmente brancos (albinos), algumas vezes rosados ou violáceos (Senseman, 2007). Estes tecidos são normais, exceto pela falta de pigmentos verdes (clorofila) e amarelos.

Com relação ao comprimento das plantas, constatou-se efeito significativo $(P<0,05)$ dos herbicidas testados $(\mathrm{F}=27,47 ; \mathrm{F}=114,68$; $\mathrm{F}=118,15$ para milho, rabanete e abóbora, respectivamente) e das concentrações ( $\mathrm{F}=3,76$; $\mathrm{F}=80,64 ; \mathrm{F}=135,79$ para milho, rabanete $\mathrm{e}$ abóbora, respectivamente) assim como da interação entre os fatores $(\mathrm{F}=2,60 ; \mathrm{F}=29,30 ; \mathrm{F}=17,28$ para milho, rabanete e abóbora, respectivamente).
A planta indicadora de milho teve seu crescimento influenciado pelo herbicida clomazona na menor e maior concentração testada $\left(1,0\right.$ e $\left.100,0 \mathrm{mg} \mathrm{kg}^{-1}\right)$, apresentando $21 \%$ e $18 \%$ de inibição, respectivamente, comparado ao tratamento controle (Tabela 1). De acordo com as consequências do mecanismo de ação do produto, devido à falta de clorofila, após a aplicação do produto, o crescimento da planta continua, contudo, após alguns dias a planta cessa o crescimento e começam a surgir manchas necróticas, como observado em nossos estudos (Ferhatoglu \& Barret, 2006).

Plantas de milho expostas à atrazina apresentaram sinais semelhantes ao observado na exposição à clomazona, entretanto com clorose menos acentuada. Para este herbicida, a intoxicação foi visível a partir da concentração de $1,0 \mathrm{mg}$ i.a. $\mathrm{kg}^{-1}$, no entanto o nível máximo de intoxicação observado foi de $40 \%$, sendo esse nível proporcionado a partir de $50,0 \mathrm{mg}$ i.a. $\mathrm{kg}^{-1}$. Coincidindo com essa baixa intoxicação, a altura das plantas não foi influenciada por nenhuma concentração testada de atrazina. As plantas de rabanete expostas à atrazina apresentaram sinais e níveis de intoxicação semelhantes ao observado para clomazona e, assim como para as plantas de milho, este herbicida não influenciou o crescimento das plantas. Marchesan et al. (2011) verificaram que 21 DAA de atrazina ( 500 g i.a. ha $\left.{ }^{-1}\right)$ em plantas de rabanete exibiram intoxicação em taxa superior

Tabela 1. Efeito das concentrações de bentazona, atrazina e clomazona sobre o comprimento das plantas de milho (Zea mays), rabanete (Raphanus sativus) e abóbora (Cucurbita moschata).

\begin{tabular}{|c|c|c|c|c|c|c|c|}
\hline \multirow{2}{*}{$\mathbf{0 , 0}$} & \multicolumn{7}{|c|}{ Concentrações $\left(\mathrm{mg} \mathrm{kg}^{-1}\right)$} \\
\hline & 1,0 & $\mathbf{1 0 , 0}$ & 25,0 & 50,0 & 75,0 & 100,0 & \\
\hline Herbicidas & \multicolumn{7}{|c|}{ Milho } \\
\hline Bentazona & $36,50 \mathrm{Aa}$ & $36,10 \mathrm{ABa}$ & $34,00 \mathrm{Aab}$ & $30,50 \mathrm{Aab}$ & $34,10 \mathrm{Bab}$ & $28,00 \mathrm{Bb}$ & $30,10 \mathrm{Bab}$ \\
\hline Atrazina & $38,80 \mathrm{Aab}$ & $36,90 \mathrm{Ab}$ & $38,40 \mathrm{Aab}$ & $36,40 \mathrm{Ab}$ & $44,80 \mathrm{Aa}$ & $41,00 \mathrm{Aab}$ & $40,40 \mathrm{Aab}$ \\
\hline Clomazona & $38,80 \mathrm{Aa}$ & $30,80 \mathrm{Bb}$ & $34,90 \mathrm{Aab}$ & 36,30Aab & $36,60 \mathrm{Bab}$ & $31,60 \mathrm{Bab}$ & $31,00 \mathrm{Bb}$ \\
\hline \multirow[t]{2}{*}{ C.V. (\%) } & 15,95 & & & & & & \\
\hline & \multicolumn{7}{|c|}{ Rabanete } \\
\hline Bentazona & $14,10 \mathrm{Aab}$ & $15,40 \mathrm{Aab}$ & $13,20 \mathrm{Ab}$ & $16,40 \mathrm{Aa}$ & $0,00 \mathrm{Bc}$ & $0,00 \mathrm{Bc}$ & $0,00 \mathrm{Bc}$ \\
\hline Atrazina & $14,10 \mathrm{Aab}$ & $14,10 \mathrm{Aab}$ & $14,90 \mathrm{Aa}$ & $14,20 \mathrm{Aab}$ & $13,40 \mathrm{Aab}$ & $11,90 \mathrm{Ab}$ & $12,20 \mathrm{Aab}$ \\
\hline Clomazona & $14,80 \mathrm{Aa}$ & $14,60 \mathrm{Aa}$ & $15,00 \mathrm{Aa}$ & $14,80 \mathrm{Aa}$ & $12,40 \mathrm{Aab}$ & $10,70 \mathrm{Ab}$ & $10,10 \mathrm{Ab}$ \\
\hline \multirow[t]{2}{*}{ C.V. $(\%)$} & 18,99 & & & & & & \\
\hline & \multicolumn{7}{|c|}{ Abóbora } \\
\hline Bentazona & $17,06 \mathrm{Aa}$ & $15,28 \mathrm{Aa}$ & $6,59 \mathrm{Bb}$ & $6,28 \mathrm{Bbc}$ & $5,06 \mathrm{Bbc}$ & $3,81 \mathrm{Bc}$ & $3,58 \mathrm{Bc}$ \\
\hline Atrazina & $16,49 \mathrm{Aa}$ & $13,65 \mathrm{Ab}$ & $14,90 \mathrm{Aab}$ & $12,75 \mathrm{Abc}$ & $12,44 \mathrm{Abc}$ & $10,55 \mathrm{Ac}$ & $12,70 \mathrm{Abc}$ \\
\hline Clomazona & $17,06 \mathrm{Aa}$ & $14,10 \mathrm{Ab}$ & $7,35 \mathrm{Bc}$ & $3,70 \mathrm{Cd}$ & $1,50 \mathrm{Cd}$ & $2,70 \mathrm{Bd}$ & $2,170 \mathrm{Bd}$ \\
\hline C.V. (\%) & 21,68 & & & & & & \\
\hline
\end{tabular}

*Letras maiúsculas iguais na coluna e minúsculas na linha não diferem pelo teste de Tukey p>0,05. C.V. = coeficiente de variação. 
a $80 \%$, progredindo com o passar dos dias. Os mesmos autores verificaram que o comprimento das plantas também foi influenciado pelo herbicida, mesmo em níveis baixos do produto ( $150 \mathrm{~g}$ i.a. ha ${ }^{1}$ ), diferindo dos resultados observados em nosso estudo, possivelmente devido à maior concentração testada pelos autores.

Para as plantas de abóbora, atrazina proporcionou necrose das plantas a partir da concentração $75 \mathrm{mg}$ i.a. $\mathrm{kg}^{-1}$, causando níveis de $100 \%$ de intoxicação. Diferente das plantas de milho e rabanete, as plantas de abóbora tiveram seu crescimento influenciado por atrazina a partir da menor concentração (17\%), comparado ao controle, e maior redução (36\%) observada na concentração $75 \mathrm{mg}$ i.a. $\mathrm{kg}^{-1}$. As diferenças na resposta de altura das plantas entre as espécies avaliadas com relação aos herbicidas inibidores do FSII estão relacionadas à sensibilidade inicial das plantas que podem variar desde sua entrada na planta, sua translocação, tempo e intensidade de exposição de partes da planta ao obstáculo, assim como diferenças na metabolização do produto (Ventrella et al., 2010). Tal fato se explica porque as taxas de metabolização do herbicida são mais pronunciadas em determinadas espécies, principalmente em estádios iniciais (Ventrella et al., 2010). No entanto, é possível que a atividade das enzimas metabolizadoras não seja suficiente para evitar que o efeito tóxico de atrazina se intensifique com o decorrer do tempo, o que provoca redução das diferenças entre as espécies (Marchesan et al., 2011). Vidal et al. (2000), em teste de seletividade de curcubitáceas a fluazifop-p-butil, observaram que abobrinha, melancia e moranga são tolerantes a este herbicida, já melão e pepino demostraram sensibilidade ao mesmo produto. Nunes \& Vidal (2009) verificaram que Curcubita pepo é uma boa planta indicadora de atrazina e imazaquin no solo, porém não é indicada para quantificação destes no solo, pois estes produtos reduzem a estatura e área foliar a ponto de não ser possível realizar análises quantitativas.

A clomazona e bentazona causaram limitação no porte das plantas de milho, clorose no limbo foliar e necrose nos bordos foliares, entretanto, a clorose foi menos acentuada. Maior nível de intoxicação foi observado na concentração $50,0 \mathrm{mg}$ i.a. $\mathrm{kg}^{-1}$, sendo as demais concentrações inferiores a esta. Embora tenha favorecido a intoxicação, esta concentração não influenciou a altura das plantas de milho, bem como as demais concentrações testadas, exceto $75,0 \mathrm{mg}$ i.a. $\mathrm{kg}^{-1}$ que causou redução de $23 \%$ na altura das plantas (Tabela 1 ).

As plantas de rabanete expostas a $50 \mathrm{mg}$ i.a kg-1 de bentazona apresentaram intoxicação de $100,0 \%$, sendo o mesmo observado nas concentrações de 75,0 e 100,0 mg i.a. $\mathrm{kg}^{-1}$. O nível alto de intoxicação dessas plantas expostas à bentazona resultou na morte delas e, em consequência, inibição do crescimento das plantas (Tabela 1). Para as plantas de abóbora, bentazona proporcionou necrose a partir da concentração de 50,0 mg i.a. $\mathrm{kg}^{-1}$, porém nível de intoxicação de $100 \%$ a partir de $75,0 \mathrm{mg}$ i.a. $\mathrm{kg}^{-1}$ (necrose total das plantas). $\mathrm{O}$ crescimento dessa planta foi influenciado a partir da concentração $10,0 \mathrm{mg}$ i.a. $\mathrm{kg}^{-1}$, sendo a maior redução na altura das plantas $(78,0 \%$ e $79,0 \%)$ observada em 75,0 e $100,0 \mathrm{mg}$ i.a. $\mathrm{kg}^{-1}$, respectivamente.

A clorose foliar que ocorre após o tratamento com bentazona é devido a rompimentos da membrana dos pigmentos causados pela peroxidação de lipídios (ácidos graxos insaturados) da membrana (Powles $\& Y u, 2010)$. No entanto, não foram observadas alterações no comprimento das plantas de milho quando expostas à bentazona e às concentrações testadas de atrazina, corroborando os resultados observados por Dayan et al. (2009) quando expuseram plantas de milho à atrazina e observaram que a taxa de transporte de elétrons foi reduzida apenas em 30\% em 24 horas após a aplicação, caracterizando-a como planta tolerante a este herbicida. Segundo Silva et al. (2007), algumas espécies de plantas, como o milho e sorgo, em suas raízes ou em outras partes, possuem enzimas capazes de metabolizar as moléculas destes herbicidas, neste caso, as glutationa- $S$-transferases, devido à rápida degradação da molécula por meio de reações de hidroxilação, dealquilação, ou ainda a conjugação dessa molécula com polipeptídios naturais, transformam rapidamente estes produtos tóxicos em não tóxicos. O contrário foi observado para a planta indicadora de rabanete, a qual teve $100 \%$ de intoxicação e seu crescimento totalmente inibido quando exposta à bentazona a partir da concentração $50 \mathrm{mg}$ i.a. $\mathrm{kg}^{-1}$.

\section{Conclusões}

A planta de milho é potencial indicadora do herbicida clomazona, enquanto as plantas de rabanete e abóbora são potenciais indicadoras dos 
três herbicidas para ensaios rápidos de toxicidade aguda com baixo custo.

\section{Agradecimentos}

Este trabalho foi financiado pela Fundação de Amparo à Pesquisa do Estado de São Paulo, Proc. 2013/10462-1, como bolsa de pesquisa científica para o primeiro autor.

\section{Referências}

Asociación Latinoamericana de Malezas - ALAM. (1974). Recomendaciones sobre unificación de los sistemas de evaluación en ensayos de control de malezas. ALAM, 1(1), 35-38.

Associação Brasileira de Normas Técnicas ABNT. (2009) Qualidade de solo - Determinação dos efluentes na flora terrestre. Parte 2. Efeitos de substâncias químicas na emergência e no crescimento de vegetais superiores (NBR ISSO 11269-2:2009). Rio de Janeiro: ABNT.

Barbosa, J.C., \& Maldonado Júnior, W. (2013). AgroEstat - Sistema para análises estatísticas de ensaios agronômicos. Version 1.1.0.668. Jaboticabal: [s.n.].

Brighenti, A. M., Moraes, V. J., Oliveira Junior, R. S., Gazziero, D. L. P., Voll, E., \& Gomes, J. A. (2002). Persistência e fitotoxicidade do herbicida atrazine aplicado na cultura do milho sobre a cultura do girassol em sucessão. Planta Daninha, 20, 291-297.

Colbach, N., \& Stéphane Cordeau, S. (2018). Reduced herbicide use does not increase crop yield loss if it is compensated by alternative preventive and curative measures. European Journal of Agronomy, 94, 67-78.

Dan, H. A., Dan, L. G. M., Barroso, A. L. L., Procópio, S. O., Oliveira Junior, R. S., Assis, R. L., Silva, A. G., \& Feldkircher, C. (2011). Atividade residual de herbicidas pré-emergentes aplicados na cultura da soja sobre o milheto cultivado em sucessão. Planta Daninha, 29, 437-445.

Dayan, F. E., Trindade, M. L. B., \& Velini, E. D. (2009). Amicarbazone, a new photosystem II inhibitor. Weed Science, 57, 579-583.

Douglass, J. F., Radosevich, M., \& Tuovinen, O. H. (2017). Microbial attenuation of atrazine in agricultural soils: biometer assays, bacterial taxonomic diversity, and catabolic genes. Chemosphere, 176, 352-360.

Ferhatoglu, Y., \& Barret, M. (2006). Studies of clomazone mode of action. Pesticide Biochemistry and Physiology, 85, 7-14.

Marchesan, E. D., Dedordi, G., Trezzi, M. M., Vidal, R. A., \& Dick, D. P. (2011). Seleção de espécies bioindicadoras para uso em bioensaios de lixiviação e persistência de atrazina no solo. Pesticidas: Revista de Ecotoxicologia e Meio Ambiente, 21, 47-54.

Nogueira, C. H. P., \& Correia, N. M. (2016). Selectivity of herbicides bentazon and nicosulfuron for Crotalaria juncea intercropped with maize culture. Planta Daninha, 34, 747-757.

Nunes, A. L., \& Vidal, R. A. (2009). Seleção de plantas quantificadoras de herbicidas residuais. Revista de Ecotoxicologia e Meio Ambiente, 19, 19-28.

Nyffeler, A., Gerber, H. R., Hurle, K., Pestemer, W., \& Schmidt, R. R. (1982). Collaborative studies of dose-response curves obtained with different bioassay methods for soil-applied herbicides. Weed Research, 22, 213-222.

Organization for Economic Co-operation, Development-OECD. (1984). Terrestrial plants: growth tests. OECD Guidelines for testing of chemicals (No. 208). Paris: OECD.

Powles, S. B., \& Yu, Q. (2010). Evolution in action: plants resistant to herbicides. Annual Review of Plant Biology, 61, 317-347.

Reis, M. R., Silva, A. A., Costa, M. D., Guimarães, A. A., Ferreira, E. A., Santos, J. B., \& Cecon, P. R. (2008). Atividade microbiana em solo cultivado com cana-de-açúcar após aplicação de herbicidas. Planta Daninha, 26, 323-331.

Rodrigues, B. N., \& Almeida, F. S. (2018). Guia de Herbicidas (7. ed., 697 p.). Londrina: Ed. dos Autores.

Sanchez, V., Lopez-Bellido, F. J., Canizares, P., \& Rodríguez, L. (2017). Assessing the phytoremediation potential of crop and grass plants for atrazinespiked soils. Chemosphere, 185, 119-126. 
Scheil, V., Kienle, C., Osterauer, R., \& Kohler, H. (2009). Effects of 3,4-dichloroaniline and diazinon on different biological organisation levels of zebrafish (Danio rerio) embryos and larvae. Ecotoxicology (London, England), 18, 355-363.

Senseman, S. A. (2007). Herbicide handbook (9th ed.). Lawrence: Weed Science Society of America.

Silva, C. M. M., Freitas, S. P., \& Rosa, R. C. C. (2007). Efeito residual da aplicação de fluazifopp-butil + fomesafen em solos com plantas-teste. Ciência Rural, 37, 1450-1452.

Souza, A. P., Prates, H. T., Ferreira, F. A., Reis, E. L., \& Jordão, C. P. (1999). Lixiviação do glyphosate e do imazapyr em solos com diferentes texturas e composição química. II. Método analítico. Planta Daninha, 17, 245-262.

United State of America Agency Environmental Protection-USEPA. (2002). Methods for measuring the acute toxicity of effluents and receiving waters to freshwater and marine organisms (275 p.). USA: USEPA.

Ventrella, A., Catucci, L., \& Agostiano, A. (2010). Herbicides affect fluorescence and electron transfer activity of spinach chloroplasts, thylakoid membranes and isolated Photosystem II. Bioelectrochemistry (Amsterdam, Netherlands), 79, 43-49.

Vidal, R. A., Kruse, N. D., Fleck, N. G., \& Merotoo, J. R. A. (2000). Seletividade do herbicida fluazifopp-butil para cucurbitáceas. Planta Daninha, 18, 413-417. 